Three tasks for mediatization research contributions to an open agenda

Ekstrøm, Mats; Fornäs, Johan; Jansson, André; Jerslev, Anne

Published in:

Media, Culture \& Society

DOI:

$10.1177 / 0163443716664857$

Publication date:

2016

Document version

Peer reviewed version

Citation for published version (APA):

Ekstrøm, M., Fornäs, J., Jansson, A., \& Jerslev, A. (2016). Three tasks for mediatization research: contributions to an open agenda. Media, Culture \& Society, 38(7), 1090-1108. https://doi.org/10.1177/0163443716664857 


\title{
Three Tasks for Mediatization Research: Contributions to an Open Agenda
}

\begin{abstract}
Based on the interdisciplinary experience of a Swedish research committee, this article discusses critical conceptual issues raised by the current debate on mediatization - a concept that holds great potential to constitute a space for synthesized understandings of media related social transformations. In contrast to other, more metaphorical constructions, mediatization can be studied empirically in systematic ways through various sub-processes that together provide a complex picture of how culture and everyday life evolve in times of media saturation. The first part of this article argues that mediatization researchers have sometimes formulated too grand claims as to mediatization's status as a unitary approach, a meta-theory or a paradigm. Such claims have led to problematic confusions around the concept and should be abandoned in favour of a more open agenda. In line with such a call for openness, the second part of the article introduces historicization, specification and measurability as three trans-disciplinary and trans-paradigmatic tasks for the contemporary mediatization research agenda.
\end{abstract}

Keywords: mediatization, media studies, history, measurability, research policy, everyday life

\section{Setting the Mediatization Agenda}

Mediatization is indeed a recurrent diagnosis today - in public debate, in social and cultural life, as well as within the humanities and social sciences (Kaun, 2011; Kaun and Fast, 2014). It serves as a synthesizing formula to cover interrelated processes such as the growth in number, diversity and reach of communication media; their multiplying efficiency in terms of speed, storage and penetrating capacity; the increasing portion of people's daily lifetime spent on media uses; the growing influence of media institutions and industries; and the allegedly growing general significance of media texts and technologies in widening spheres and fields of life, society and culture. In all cultural subfields, heightened media presence seems to change the conditions for the making, dissemination and use of sounds, images 
and texts, with ambiguous implications for aesthetics, industries, education, policy and publicness. Ordinary everyday life too is affected, not least by online networks of social media.

While public discussions in many fields seem to take such diagnoses for granted, the concept of mediatization has ignited heated debates in the field of media and communication studies. While the proponents of the concept champion its potentials as a new paradigm for media studies, opening up for non media-centric perspectives and interdisciplinary collaboration, sceptics question its explanatory status and value. Lundby (2014) has edited a recent volume of the respected series of 'Handbooks of Communication Science', which is devoted to explore the multiple facets of the concept, and an interesting and nuanced debate on its implications has recently taken place in Media, Culture and Society (Deacon and Stanyer, 2014, 2015; Hepp, Hjarvard and Lundby, 2015; Lunt and Livingstone, in press). The explosive growth of this field - with ECREA's Temporary Working Group 'Mediatization' (established 2011) advancing in autumn 2015 to the status of a full Section - indicates a need for media studies to engage in self-reflexive discussions, in order to deal with those contemporary processes of transformation which affect society and the media as well as our own research methods. Most projects and publications in the field focus on specific research issues, and in this situation the vivid mediatization debate testifies to a need for synthesizing and interdisciplinary reflection that can generate broader and more complex understandings of media's role in society.

However, the agendas and claims of research on mediatization diverge significantly depending on research area and underlying perspectives. For instance, whereas the mediatization of politics has been researched in a focused manner, mostly from an institutionalist viewpoint, studies of corresponding processes in culture and everyday life have been dispersed on insufficiently communicating disciplines and with many unsolved theoretical issues. Notably, the fundamental question of "what counts" as mediatization remains largely unsolved, which in turn has to do with the fact that there are disparate understandings of what kind of concept mediatization is. This was why the Bank of Sweden Tercentenary Foundation (Stiftelsen Riksbankens Jubileumsfond, RJ) formed a 
sector committee on the mediatization of culture and everyday life, which commenced by hosting an exploratory workshop in August 2011 and ended in March 2016. This mediatization committee gathered media scholars and professionals through a wide range of activities and specialized networks, and also produced two reports that mapped Swedish and international research and debates in the field (references removed). ${ }^{1}$

Based on the interdisciplinary experience of the sector committee, in this article we discuss critical conceptual issues raised by the current debate and suggest three important tasks for the contemporary mediatization research agenda. It is our conviction that the concept holds great potential to constitute a space for synthesized understandings of media related social transformations. We think that mediatization is a concept that, in contrast to more metaphorical constructions like for example 'media life' (Deuze, 2011), can be studied empirically in systematized ways through various sub-processes that together provide a complex picture of how culture and everyday life evolve in times of media saturation. As stated in the first part of this article, however, we also believe that dedicated mediatization researchers have sometimes formulated too grand claims as to mediatization's status as a unitary approach, a meta-theory or a paradigm. Such claims have led to problematic confusions around the concept and should, in our view, be abandoned in favour of a more open agenda. In line with such a call for openness, in the second part of the article we introduce historicization, specification and measurability as three trans-disciplinary and trans-paradigmatic tasks for mediatization research.

\section{Claims, Confusions and Dynamic Diversity}

Discussions on assumed key concepts are revitalizing and important in prompting scholars to reconsider the definitions of commonly used concepts and the explanatory power of alternative theories. One might argue that the ubiquitous organization of research in specialized short-term project-funded empirical studies provides limited space for in-depth

\footnotetext{
1 [Note on the participants of the sector committee and the committee's activities and networks will be added along with authors' acknowledgments.]
} 
theoretical discussions, while also making such discussions particularly important (cf. Hepp, Hjarvard and Lundby, 2015: 316).

In media research, much theoretical rethinking is driven by the rapid development of digital media. Concepts are invented to better understand how social and cultural practices - in everyday life and societal institutions - are shaped and transformed in the context of 'new' media technologies, media forms and institutions. These transformations, which ultimately problematize the very object of media research, have also spurred the discussions around mediatization. Whilst the concept of mediatization has been sporadically used by various authors in social science and cultural theory (e.g. Manheim, 1933/1979; Baudrillard, 1972/1981; and Habermas, 1981/1987), and applied by media researchers over several decades to explain institutional transformations mainly within politics (e.g., Asp, 1990; Mazzoleni and Schulz, 1999), it is in the last decade that mediatization is advocated as a key concept for the general study of media in culture and society. Before the early 2000s the usages of the term mediatization within more culturally oriented approaches (within and beyond media studies) were relatively dispersed and incoherent also regarding terminology - including overlapping notions of 'mediation', 'mediazation' and 'mediatization' (cf., e.g., Baudrillard, 1972/1981; Martín-Barbero, 1993; Thompson 1995; Virilio, 1995; Silverstone, 1999; references removed; see also Bolin, 2014). Since then, more committed theoretical agendas and approaches have been outlined and a number of empirical studies have contributed novel knowledge to the field (Lundby, 2014). The conceptualizations of mediatization, however, show a mixture of far reaching claims and fundamental ambiguities that risk being obstructive rather than productive. The expanded use of the term has led to a situation where the inner core of the field develops general theories and what Jensen (2013: 205, 218, referring to Blumer 1954) critically describes as 'definitive' concepts of mediatization, whereas the more general export of the term turns it into a vaguely defined 'buzzword'. Based on our experiences from the above mentioned activities over three years, media scholars today seem divided into five groups in their relations to the concept: the highly committed 'mediatization researchers'; those who occasionally apply a theoretically informed version of the concept in empirical 
analyses; those who refer to the term without much theoretical implications; some who are openly critical; and a large group of media scholar who are confused when trying to understand what kind of theory is actually proposed.

The different understandings of mediatization partly relate to different genealogies of the concept (see the introduction to Lundby, 2014), and the transformations of the concept from distinct theoretical contexts to either more universal theories or an umbrella concept for a network of researchers who share interests but not necessarily theoretical perspectives. The literature on mediatization has contributed theoretically on basically two levels: first, explaining concrete processes of mediatization in relation to mechanisms of institutionalization, dependence and adaptation; second in inspiring a broader discussion on the very object and orientation of media research.

However, the confusions around the concept, we argue, relate not just to the existence of different theories of mediatization, but to the far-reaching claims related to the concept. These claims are articulated in arguments proposing that mediatization at the same time refers to (1) a particular approach within the field; (2) a meta-theory or even a grand theory for media studies; and (3) a paradigmatic shift in media- and communication research at large. We find each of these claims problematic, and instead propose that the concept of mediatization should better be understood as referring to a meta-process whose complexity and contextual manifestations require a research agenda that invites a spectrum of diverse theories and analyses focusing on media-related transformations in society.

The emphasis on long-term media related social change seems to constitute a common denominator for most mediatization research today (see Lundby, 2014: 19). Along these lines, a number of overlapping definitions are suggested in the literature, regardless of research focus (e.g., Couldry and Hepp, 2013; Hepp, 2013: 619; Hjarvard, 2013: 17; Livingstone and Lunt, 2014: 704; references removed). The definitions are typically rather open (which is an advantage), but they do state that the concept applies to long-term transformations of socio-cultural practices and institutions, assumed to be related to an 
increase in the spread and implications of media as technologies, institutions and cultural forms. However, if this broad definition invites contributions from various approaches and disciplines, developing different theories of media related transformations (using the term mediatization or not), other definitions, and certain extensions of these definitions, are more problematic.

\section{Mediatization research as an approach}

In the literature, 'mediatization research' is frequently referred to as a particular approach within media research, in marked contrast to a research focusing on more specific and limited instances of mediated communication (Lundby, 2009; Couldry and Hepp, 2013: 197). For instance, Couldry and Hepp (2013: 191) argue that mediatization captures 'the broad consequences for everyday life and practical organization (social, political, cultural, economic) of media [...] that cannot be reached simply by accumulating more and more specific studies that analyze this newspaper, describe how that program was produced, or

trace how particular audiences make sense of that film on a particular occasion.' It is easy to agree that such research has limited possibilities to contribute knowledge of broader consequences and transformations. However, such lines of argumentation seem to rely on a caricature of mainstream media research. Research simply analyzing how a programme was produced without relating to general questions and theoretical ideas would hardly qualify as good research at all. What is more, much media research is affiliated to joint efforts of theory development aiming to understand how media (re)shape and transform everyday practices, social relationships, selves and identities, orientations in time and space, relations between private and public, political power, etc. This is true not least in relation to the extensive research on social media. The orientation to 'broader consequences' and 'social and cultural transformations' is hardly unique to 'mediatization research', although this umbrella concept may help to describe common interests, efforts and achievements. However, if agreed that the concept of mediatization refers to the various ways in which media shape social and cultural transformations, it has to be 
recognized that a large group of scholars do research on mediatization without making use of the concept.

The discussions on mediatization draw attention to the importance of developing largescale historical studies to analyse the role of changing media environments in long-term processes of social change. However, questions about how socio-cultural practices transform in relation to media technologies and cultural forms, in different historical context, are (and have been) a general interest in media research, investigated in the context of different disciplines, theories and methodological approaches. The agenda of mediatization research, we argue, should be open to these influences, which can contribute to the consolidation of a pluralistic research field where different positions are to be found.

\section{A meta-theory and a grand theory}

Based on the idea of mediatization as a meta-process, it may seem consequentially and almost natural to propose a general theory of the long-term processes of media related social and cultural transformations. Hepp (2012: 10, referring to Krotz) argues that metaprocesses such as individualization and mediatization 'correspond' to meta-theory, defined as 'theoretical narratives that cross various areas of phenomena' (Hepp, 2012: 10). Such narratives are assumed to explain what Krotz (2007: 27) describes as 'long-term and cultural-crossing changes'. In social science, the concept of meta-theory commonly refers to theories about - and the study of - the criteria of scientific theories and their ontological and epistemological assumptions (Ritzer 1990; Morrow and Brown 1994:118). In the above referred to discussion on mediatization, where meta-theory and meta-process are associated, however, 'meta' rather refers to a level of theoretical generalization. Theories can be general in at least two different ways; in claiming to capture all-encompassing systems and processes, aiming to totalize in this case the diverse forms of mediatization into a single theory (i.e., Grand theories); or in identifying abstract (and distinct) social processes, structures, relationships and mechanisms (cf. Danermark et al. 2002: 138). 
Based on the understanding of mediatization as long-term processes of social transformation, it is perhaps tempting to aim for a general theory that integrates and explains processes of mediatization across time and social-cultural contexts; a grand theory of mediatization that incorporates most other social theories of relevance. We, however, believe such attempts are at odds with the idea of complex meta-processes and should therefore be abandoned, together with the idea of mediatization as a constant, steady and linear process of growth from the start of human communication until today. Grand or totalizing (meta-)theoretical claims are not advisable (cf Rakow, 2013: 194), and they hardly stimulate the multidisciplinary research required to understand and explain diverse processes and manifestations of mediatization in different contexts.

The latter form of generalization, referring to abstract relations and processes, presents a more adequate rationale for research on mediatization. As Krotz (2014) emphasizes we should also be attentive to various sub-processes of mediatization, through which the complexity and internal contradictions of mediatization can be unveiled. As examples, Krotz refers to Schulz's (2004) notions of extension, accommodation, substitution and amalgamation, which represent different facets of mediatization. We agree with what we understand as an argument for conceptualizations and analyses on different levels of abstraction. Suggestions along these lines have also been advanced by others. For example, Deacon and Stanyer (2014: 1040) suggest that one way to develop the theorizing of mediatization is to combine general conceptualizations with 'concepts at lower levels of abstractions'. Jensen (2013:218) argues that mediatization "is best understood as a broad and inclusive concept", and advocates a plurality of 'sensitizing conceptualizations' as guidance in analyzing the implications of changing media environments. Similarly, we believe such conceptualizations are advisable in analyzing mediatization processes (and sub-processes) as potentially constituted by general conditions on high levels of abstraction, and situated in concrete social, cultural and historical contexts. This view is congruent with a view of mediatization as meta-process; potentially multidimensional and non-linear; operating in different ways in different media environments. 


\section{A paradigmatic shift?}

The ground-breaking distinctiveness of mediatization research is most clearly articulated in the idea of this research representing a paradigmatic shift in media and communication research (Hepp, Hjarvard and Lundby, 2015: 315, 321; Livingstone and Lunt, 2014). There might well be an increase in empirical research focusing on long-term media related sociocultural transformations, and there are many initiatives to constitute a community for such research, through conferences, networks, special issues and edited volumes. Still, the idea of a paradigm is disputable.

Livingstone and Lunt (2014: 720) describe mediatization as an 'emergent paradigm', referring to Kuhn's (1962) seminal work and suggesting that mediatization seems to answer 'unresolved puzzles'. They add that 'more research is needed before concluding that mediatization improves on the explanatory power of its rivals'. Among these rivals they mention media ecology, actor-network theory and critical theory of technology, and they thus assume that mediatization represents a coherent theoretical approach or paradigm.

There is obviously no simple definition of what constitutes a paradigm. Kuhn himself provided multiple definitions (Masterman, 1970; Kuhn 1972). To what extent paradigms at

all exist in social science is also intensively discussed. However, according to a common interpretation (relevant also for social science) paradigms comprise ontological assumptions (in practice almost taken for granted), basic conceptualizations of the objects of research, norms, models and exemplars of appropriate methods and practices. This is what researchers more or less share and are socialized into. In media and communication research there are such differences between for example the behaviourist and quantitative research on media effects versus social constructivist approaches favouring qualitative methods. A reading of the theoretical and methodological approaches suggested by the researchers most affiliated to 'mediatization research', however, indicates that they do not share what is reasonably required to constitute a coherent paradigm or a coherent research program (cf. Jensen 2013: 218). And what is more, there are no reasons to expect 
that they should, or will in the future. What is often described as the main approaches developed in research on mediatization - institutional and cultural constructivist approaches - refer to different and competing theoretical traditions (and thus paradigms) in social science. This is what makes the research field so dynamic. To assume that for example Strömbäck's (2011; also Strömbäck and Dimitrova, 2011; Shehata and Strömbäck, 2014) work on the mediatization of politics and Hepp's (2011/2013 and 2013) research on communicative figurations are part of one paradigmatic shift is more confusing than clarifying.

\section{An open concept and an open research agenda}

Critics argue that the concept of mediatization in its present shape lacks clear 'discriminatory power' and that we 'need to know what it is not' (Deacon and Stanyer, 2014: 1039). What differentiates instances of mediatization? What is required for a media related social transformation to be an example of mediatization is obviously not easy to decide. Couldry and Hepp (2013: 197) argue that mediatization 'refers to the role of particular media in emergent processes of social and cultural change'. They find significant differences in how this role of the media has been conceptualized in terms of 'media logics', 'media specificity', 'institutionalization', or 'moulding forces'. This illustrates a prolific diversity in the theory development (see also Hepp, 2012; Lundby, 2014). However, the various conceptualizations of how mediatization works do not reduce the vagueness of the concept.

We can see at least two possible solutions to the lack of a detailed and unified definition: either by arguing for a general theory with clear demarcations of the particular transformations accounted for as mediatization, or by keeping the concept broad and open and delegate the responsibilities for clear definitions to the various theories developed within the research on media related transformations of society, culture and everyday life. We ourselves lean towards the latter alternative. We also think that this is the direction in which research on mediatization currently develops. The various research activities and debates that have taken place during the last decade have led to the establishment of a vital 
research field, in spite of the ambiguities surrounding the concept. The fact that Mediatization is now also institutionalized as a permanent section of ECREA will certainly not close these debates, but rather legitimize their prolongation and expansion into previously unaffected areas. Controversies pertaining to the field's foundational concept, mediatization, should then be seen as a sign of the field's gradual maturation, which by definition means that there will be different positions and continuous competition as to the definition of the field's key concepts and of the field itself (cf. Bourdieu, 1980/1990). So far, we have discussed some conceptual claims, confusions and challenges in contemporary research on mediatization processes, and proposed an open multidisciplinary theoretical agenda. In the second part of this article, we wish to identify some areas and approaches where new theoretical development and empirical research seem particularly called for and also potentially rewarding. Our suggestions are based on the research reviews conducted and symposia hosted by our sector committee and can thus be seen as the outcome of a relatively inductive process. As such, in line with our call for an open research agenda, the three tasks outlined below also transcend different research approaches, disciplines and paradigms.

\section{Three Tasks}

If mediatization is to be understood primarily as a unifying heuristic concept for a range of media-embedded processes of social transformation, rather than any fixed theoretical model, more precise theories and analytical frameworks are needed to develop its explanatory potentials. As a broad meta-process of media-related social transformation, mediatization thus needs to be further specified in conceptual but also empirically grounded ways. There is a need for dialogues between rich case studies and theoretical work. These needs are particularly strong in relation to the mediatization of culture and everyday life. Even though a number of committed mediatization researchers have explicitly addressed questions of culture, either in constructivist or institutionalist terms (cf., e.g., Hepp, 2013; Hjarvard, 2013; references removed), different humanities and social science disciplines have largely failed to co-operate so as to discern specificities and 
commonalities between processes identified in different cultural spheres and areas of everyday life. By cultural spheres we refer to institutionalized forms of cultural and artistic production as well as to cultural practices of the lifeworld. There are thus no clear lines of division between 'culture' and 'everyday life' as so conceived. Rather, what we refer to is precisely the interplay between different realms of 'ordinary' and 'expressive' meaning making (see Williams, 1977), and the normalizing and potentially transformative role of media within and between these realms. We thus find the commonplace opposition between constructivist and institutionalist perspectives on mediatization counterproductive, because it tends to reproduce a dichotomized view of cultural and social life. There could be many issues on our suggested open agenda for mediatization research. However, delimiting the area to culture and everyday life, we would like to propose three particularly important directions for renewed efforts. All of them derive from the initial promises of the concept of mediatization and are identified as means for moving beyond some of the current deadlocks within the field.

(1) First, there is a standing invitation to - as well as a notable lack of - historicizing research, by means of longitudinal studies or cross-temporal comparisons. (2) Second, by pointing at rather general trends in how media texts, technologies and institutions work in societies, the concept of mediatization calls for comparisons between different media forms and different communicative contexts, but at the same time much of the actual research remains stuck in traditional models of focusing one medium or spatial and social context at a time. There is therefore a need for differentiating and specifying the currently too general talk of mediatization. (3) Finally, if mediatization is a fundamental historical process activating a broad range of media, and if it contains an element of cumulative growth rather than just a non-directional series of qualitative transformations, i.e., if it involves some sense of movement from less to more significant adaptations to processes of mediation, or mediatization expanding into new domains, then empirical methods need to be developed to measure and comparatively assess the level or speed of mediatization in different timespace contexts. Here, some kind of quantitative measurability is called for, also within the realm of culture and everyday life. In the following we expand on each of these directions. 


\section{Historicity}

As a concept for certain kinds of long-term social transformations, mediatization invites historical approaches. In relation to much other media and communication research, it should - and has the potential to - focus on how media processes interact with other forms of social change. With this in mind, it is striking and so far slightly disappointing how little such actual research there is in the field. Too much of existing research has hypostasized the existence of mediatization and then focused on analysing the contemporary effects of this taken-for-granted process. We can also discern unfortunate gaps or lines of division between some leading proponents of mediatization theory and other schools of thought focusing on media history, often based on Canadian media theory, from Harold Innis, Walter J. Ong and Marshall McLuhan up to John Durham Peters in the US or Friedrich Kittler and Wolfgang Ernst in Germany, among many others. We find this hostility unfortunate, since it prevents productive dialogues that may refine the understanding of media temporalities.

Hence, mediatization needs to be historicized. Many have pointed out that there is too little research on the temporal aspects of mediatization. Several mediatization scholars (see, e.g., Hepp, 2013) have emphasized this time dimension, arguing for longitudinal studies or comparisons over longer time spans, but also for analysing generational shifts as a way of approaching long-term transformations (see also Hepp, 2011/2013, 2013; Hepp, Hjarvard and Lundby, 2015; Hepp and Krotz, 2014). Critics such as Deacon and Stanyer (2014) have likewise argued for empirical studies of change over time. They would also like to know how individual and institutional actors sometimes in various ways counteract the effects of mediatization, implying that it may not necessarily always run in the same direction. The possibility of phases of de-mediatization has also been acknowledged by proponents such as Hjarvard (2013). Lunt and Livingstone (in press) recently regarded a 'heightened historical awareness' as a key benefit of the mediatization concept, with types and scales of transformation being central issues. 
These issues have been approached by several of the Swedish networks in this field. One on 'Mediatization Times' examines how liveness and historical processes are shaped by technical infrastructures of temporality (see also Reference removed). Another on 'Media and Everyday Life' scrutinizes how new media affect daily life while in reverse vernacular routines domesticate new communicative technologies, partly neutralizing their transformative effects (Löfgren, 2009). These series of workshops, seminars, networks and reports have given ample evidence on the vitality of new research that historicizes different media fields within culture and everyday life, but also the need for interdisciplinary historical research that more systematically analyses and compares developments in for example publishing, music media and social media (Reference removed; Kaun and Fast, 2014).

How to compare levels and kinds of mediatization between different historical periods is a very complicated matter. Virtually all elements of a social and communicative situation changes over time, and it becomes extremely difficult to decide which differences are the main driving factors and which are mere side effects. It may be quite easy to compare the number of media or average hours of media use between two different years, but how to measure the role or power of media between two radically different situations some years, decades or centuries apart? There may well plausibly be fundamental processes of transformation, but how to decide precisely what is transformed by which forces? How does mediatization in this respect interact with other processes of social change, such as individualization, globalization or commercialization? (Lunt and Livingstone, in press.) These are general problems with all historical comparisons, and may explain the apparent scarcity of this type of research. Yet, if the talk of mediatization as a process of social transformation is to be qualified, such problems must be dealt with. This calls for larger and more ambitious research projects where scholars from different disciplinary backgrounds collaborate to critically assess different ways of understanding what mediatization may mean, and to test those alternative models that have been proposed, for instance concerning the balances between breaks and continuities or between linearity and reversibility. To attain this, one option is to strategically select a set of points in time and 
then make systematic comparisons of how different media were used in and had an impact on selected aspects or areas of culture and everyday life. This requires interdisciplinary collaboration and methods for contextualising the findings to sort out media changes and estimate their weight in relation to other kinds of technical, political, economic, social and cultural processes. Another model that has been tested is to map the history of a particular form of mediation in order to identify and date key transitions. This again demands a focused attention to how meanings and implications of given forms of communication may subtly change as their contextual coordinates mutate due to non-media specific social transformations. A third possibility that has also been used is to interpret generational data in order to trace the effects of shifting life course-bound media experiences. In such studies, care is needed to distinguish temporal effects of generational shifts from those bound to age, as for instance some media habits are since long common to young people of a certain age while others follow specific generational cohorts up through the ages.

\section{Specificity}

The term mediatization thus designates ways media have transformed from specific technologies of mediation into general 'moulding forces' (Hepp, 2013), with an increased influence on culture and society, as a result of both qualitative and quantitative historical changes (Lundby, 2009). The unifying term mediatization thus encourages a heightened reflexivity to such processes.

However, the term actually covers a variety of processes of transformation, which are studied across media and communication science as well as in other fields within the humanities and social science. Hence, the term encourages, even demands, crossdisciplinary studies concerned with broader societal and cultural processes and changes but also studies of the influence of particular media on particular fields and domains. Lunt and Livingstone (2015) thus call for comparative studies of the ways mediatization works 'across domains and over time'. Besides pointing out that mediatization deals with changes over time, Lunt and Livingstone imply that processes of mediatization unfold differently in different domains and may influence each other across domains in different, uneven and 
asymmetric ways. Needless to say, understood as cross-disciplinary studies, mediatization puts emphasis on media in context: the different interactions and effects of different types of media in different cultural or institutional settings.

Besides the need for historicization, there is therefore a need for specification of various forms, types and settings of mediatization. There are several dimensions to distinguish. One concerns the issue of media specificity: how processes of mediatization may differ depending on precisely which media types, genres, technologies or institutions are discussed. Another specifying dimension concerns context specificity: studying in which social (schools, politics, literature etc.) and which geographical (e.g., different countries) contexts mediatization develops.

Whereas mediatization studies call for meta-level theorizations of the influence of media on society and culture over time, there is an additional need to pay attention to the heterogeneity and uneven pace (Couldry, 2008) in these processes and study concrete examples of non-linearity and asymmetry within particular fields as well as across fields. As discussed above, mediatization is at once all encompassing and diverse, constituting at once a historical meta-process and a range of more concrete and context-specific subprocesses. Accordingly, a composite understanding of mediatization can only be reached through different approaches focusing on different configurations of media, contexts and subprocesses.

Hjarvard (2014) has recently called for mid-level institutional analyses of mediatization processes and mid-level analyses of ways media intervene and construct patterns of social interaction. He understands 'institution' very broadly as covering concrete institutions (like particular media institutions and media systems), fields like politics or sports, as well as less demarcated institutions like the home. Hjarvard points out that mid-level studies are empirically grounded and hereby argues in favour of a non-media-centric approach to mediatization, which studies the ways several 'logics' from different institutions are at work simultaneously and coalesce and interfere with each other: media logics (in the plural) and institutional logics (in the plural). 
How these modi operandi work together or against each other can be unpacked through cross-disciplinary studies and specific empirical analyses on middle and micro level. Analyses of processes of mediatization on these levels should therefore illustrate how 'there are different specificities of different media' (Hepp, 2009: 144); accordingly, how mediatization means different things and is expressed differently in different contexts. Moreover, micro- and middle level analyses should of course take into consideration in what ways or whether changing modes of communication and social interaction related to different media partake of mediatization and hence may contribute to improve our theoretical understanding of processes of mediatization (Livingstone, 2008).

One could argue that different media's different technological affordances, institutional structure and different production logics contribute differently to changes in culture and society. But how then call attention to differentiation? One solution could be to clearly situate the research by limiting the investigation to one single medium in one particular social context, for instance through studies of the changed relationship between television and the family, mapping the when, where, what and how (References removed) of the mediatization of social interaction in the family. Another solution could be to comparatively study relations between different media, while limiting the study to one particular focus or approach. A third approach to differentiation would be to map more broadly how a range of different media mediate but also mediatize a particular area of life or social practice, for example everyday life.

For example, from Craig Gilbert's 10 episode documentary An American Family, broadcast on PBS in 1973, through the Big Brother reality game show and up to the early $21^{\text {st }}$ century rise of social network media and many-to-many communication, everyday life and subjectivity enactment in the private sphere have been increasingly mediated and largely mediatized. Meyrowitz (1985) argued that television profoundly changed the relationship between the public and the private, and this trend accelerated when the 1973 observational film camera was first substituted with Big Brother's surveillance cameras and when social network media then made social interaction comprehensively and continuously communicated to an open-ended and in turn interacting audience. 
Contextualizing these changes of the mediation of everyday life in relation to the heated public debates surrounding these specific mediations of everyday life may add nuances to the often assumed linearity of this process, and call attention to discontinuities and dynamics that go against and modify the dominant trend towards mediatization.

\section{Measurability}

A significant critique against mediatization theory is that it refers to a meta-process that is so complex that it eventually tends to incorporate anything. Deacon and Stanyer (2014, 2015) hold that mediatization runs the risk of becoming a 'concept of no difference' that 'encompasses and conflates a vast range of media and communication structures, processes and practices' (2015: 657). This is an important point that should be taken as a key challenge for research on mediatization, especially within the area of culture and everyday life. Great care should be taken as to when the term mediatization is attributed, ensuring that mediatization refers to changes of a certain magnitude and that these changes involve media as an indispensable part.

As noted above, historicizing approaches constitute one antidote to slack terminology, since the dynamics of structural transformation, and thus the broader contours of a metaprocess, are often easier to detail in retrospect (revealing for instance the interplay between mediatization and other meta-processes). Another way of granting the validity of the term would be to develop ways of measuring mediatization, meaning that the degree to which various actors and individuals adapt their practices and mind-sets to media and mediation processes is quantified and thus directly comparable across time and space. The idea of measuring mediatization is not new. Within the institutionalist strand of mediatization research, quantitative studies have prevailed since the 1980s, focusing above all on the mediatization of politics. In Sweden, for instance, a number of studies have been conducted to detect how political strategies and practices have become increasingly adapted to the 'logics' of the media (e.g., Asp, 1986; Strömbäck and Dimitrova, 2011). There have also been studies on how politicians and news journalists perceive the political influence of media (e.g., Strömbäck, 2011), and on the significance of (news) media for 
gaining political knowledge (e.g., Shehata and Strömbäck, 2014). However, these studies are not concerned with the socio-cultural processes through which media themselves (i.e., as technologies and cultural properties) become indispensable to various social actors. Furthermore, if we overview mediatization research that address the broader terrain of culture and everyday life, there is a general lack of quantitative research (for exceptions see, e.g., Lindell, 2014; Reference removed).

In relation to certain aspects of institutionally organized culture, such as book publishing or music production and distribution, approaches like those applied in relation to politics and other institutional settings could be valid. To some extent it would even be possible to work retrospectively through quantitative analyses of documents like newspapers, magazines, advertising, even autobiographies, in order to see to what extent and how (different) media have affected the conditions of different cultural institutions and their key actors during different periods and in different sociocultural contexts. Such quantifying overviews could be an integral part of historicizing analyses of mediatization. However, when it comes to mediatization processes pertaining to everyday life, where institutional logics are not applicable, things get more complicated. How can we achieve valid measures of media's governing role within different realms of everyday life?

It should first be noted that there already is a great body of quantitative research within audience studies that maps out patterns of everyday media use, sometimes incorporating a longitudinal component. However, these studies have a tendency to measure only the degree to which people are using different media and for what purposes. This type of information tells us something about the saturation of media within different areas of life and in different social groups; but it is not sufficient for assessing the more qualitative significance of media within processes of social and cultural change. We should also note that the outcomes of this type of quantitative studies have not yet been systematically incorporated within the more institutionalized field of mediatization studies. A first step towards measurability is thus to overview and organize the quantitative results that have been generated in various audience-oriented projects in different parts of the world since the mid-twentieth century. Such an endeavour would be a powerful way of substantiating 
the historical claims of mediatization theory while at the same time making justice to all the research that has already been carried out. It would also be a way of discussing and gaining insights into what kinds of indicators could say something important about mediatization in future analyses.

The second step, accordingly, would be to establish a 'point zero' and to develop a coherent analytical framework for measuring the mediatization of everyday life in ways that could be repeated in different places and at different times. It would ensure that we could achieve a more nuanced and historicized understanding of mediatization in the future. This is not the place for delineating such a framework in detail, but we would like to raise three principal points as to how such measurements are to resonate with the nature of mediatization.

Firstly, what can be directly measured is not mediatization as a meta-process, but what we have referred to above as sub-processes (see Mazzoleni and Schulz, 1999; Schulz, 2004; Krotz, 2014). Schulz (2004) has identified four such sub-processes: extension (growing capabilities due to media), substitution (when non-mediated practices become dependent on media or new media take the place of old ones), amalgamation (when media practices become intertwined with other practices), and accommodation (when different actors adapt their modes of thinking and acting to the existence of media). The relevance and implications of these very sub-processes, as well as their applicability within the realm of everyday life, can of course be questioned (see, e.g., Hjarvard, 2008). The point, however, is that this type of categorizations are necessary for operationalizing media related change and ultimately generating results that together can make up a more complex picture of how mediatization unfolds as a meta-process over time and in different realms and strata of society.

Secondly, measurements of mediatization should not be technology-centric, but rather focus on certain realms of activity. In line with our call for specification and differentiation, as discussed above, one could study, for example, social fields following Bourdieu (1980/1990) or what Giddens (1991: 83) calls lifestyle sectors; 'a time-space "slice" of an 
individual's overall activities, within which a reasonably consistent and ordered set of practices is adopted and enacted'. Whereas the role of particular technologies is clearly an interesting topic to mediatization research, a central task is to grasp complex changes that involve a large variety of media. For example, if people no longer adapt their everyday routines to the schedules of television or no longer feel obliged to have a landline telephone at home, such alterations should not be taken as evidence that mediatization has stopped. Measurements of everyday mediatization processes need to pertain to realms of activity that are relatively stable (as categorical entities) over time and can be found in most parts of society. In order to identify such areas, valuable insights could be gathered from ethnographic accounts of, for example, the domestication of media within households (see Hartmann, 2009) or media related alterations pertaining to work-life balance (see Gregg, 2011).

Thirdly, as indicated above, mediatization research needs to move beyond measurements of the mere uses of media in order to grasp qualitative changes in terms of how people adapt to the media and to what extent media become indispensable to everyday life (References removed). It is not enough to just count the number of broadband subscribers or the amount of time people spend on Facebook. What is important is to account for whether and how these developments imply that different areas of practice become reliant on media and to explore how people feel about such transformations. A number of recent studies have used qualitative methods for grasping, for instance, how people experience moments of disconnection or information overload (see Bengtsson, 2015; Paasonen, 2015). Such complex experiences are of course difficult to measure, but one should not underestimate the possibility of using survey methods for asking individuals about whether media are mandatory parts of their lifestyles; to what extent they think that their activities are governed by media forms, and whether such relations have changed over time. The deeper meanings and social dynamics of such changes should of course be detailed through further ethnographically oriented studies.

An objection to these points could be that survey research has become increasingly problematic to carry out in a pluralized and mediatized society, where answering rates are 
getting lower and lower (especially in certain groups). However, there are various ways of refining survey methods in order to compensate for such problems. Furthermore, quantitative accounts can be achieved by means of experimentally oriented panel-data and so called 'big data'. In an increasingly interactive and algorithmically steered media environment we should explore the possibilities of using user generated data as entry points for studying mediatization processes. One problem with such data, obviously, is that they do not tell us much, if anything, about actual experiences and modes of handling media related transformations in social life. What they could provide, however, are statistical representations of how various lifestyle sectors and practices are successively moving away from physical space and into media space, making online technologies indispensable to for example retailing (Turow, McGuigan and Maris, 2015), and how people's cultural consumption patterns, ultimately their tastes, are becoming curated by the data mining of so-called 'infomediaries' (Morris, 2015). It remains an open question to what extent this type of data sources can be made accessible to academic research and designed in ways that sustain mediatization research in a meaningful way.

\section{Conclusion}

Based on a wide range of activities to investigate and further develop discussions and perspectives on mediatization, carried out by and around the Swedish foundation Riksbankens Jubileumsfond's Sector Committee, we have here in three steps summed up our findings and highlighted some key provisions for advancing research on mediatization. First, a brief outline was offered of how the concept has flourished - explicitly or implicitly - in contemporary social and cultural debates, as well as in everyday life, and how the generally intensified attention to media aspects of societal transformations has resulted in the establishment of a growing and vital field of interdisciplinary media and communication research.

Second, we have critically discussed some of the main theoretical issues and obstacles encountered in this field of research, including the problems of defining mediatization as a 
particular research area, as a general meta-theory for contemporary media studies at large, or as a unified scientific paradigm.

Third, we have identified three directions where we firmly believe that intensified efforts are needed from both research groups and funding agencies, in order to move forward and make it possible to harvest the crops that are maturing in this field: (1) historizing investigations of temporal transformation processes; (2) specifying differences between different media circuits and between different contexts; and (3) searching for measurable scales of mediatization, which would allow for meaningful comparisons.

With this, we hope to have drawn some useful conclusions from four years of collective investigations and debates, hopefully inspiring other Swedish, Nordic, European and global scholars to continue exploring the complex dynamics and consequences of mediatization, in close interaction between disciplines as well as with non-academic media-related spheres and institutions in cultural and social life.

\section{References}

Asp, K (1990) Medialization, media logic and mediarchy. Nordicom Review 11(2): 47-50.

Baudrillard, J (1972/1981) For a Critique of the Political Economy of the Sign. St. Louis: Telos.

Bengtsson, S (2015) An ethics of ambiguity in a culture of connectivity? Paper presented at the international research workshop Mediatisation of Culture and Everyday Life, 23-24 April 2015, Stockholm, Sweden.

Blumer, H (1954) What is wrong with social theory? American Sociological Review 19: 3-10. Bolin, G (2014) Institution, technology, world: Relationships between the media, culture, and society. In: Lundby, K (ed.) Mediatization of Communication (Handbook of Communication Sciences, Vol 22). Berlin: De Gruyter Mouton.

Bolin, Göran (2016, in review) The rhythm of ages analysing mediatization through the lens of generations. Article manuscript for International Journal of Communication.

Bourdieu, P (1980/1990) The Logic of Practice. Cambridge: Polity Press. 
Couldry, N (2004) Theorising media as practice. Social Semiotics 14(2): 115-132.

Couldry, N (2008) Mediatization or mediation? Alternative understandings of the emergent space of digital storytelling. New Media and Society 10(3): 373-391.

Couldry, N and Hepp, A (2013) Conceptualizing mediatization: Contexts, traditions, arguments. Communication Theory 13(3): 191-202.

Danermark, B, Ekström, M, jacobsel, L and Karlsson, J (2002) Explaining Society: Critical Realism in the Social Sciences. London: Routledge.

Deacon, D and Stanyer, J (2014) Mediatization: Key concept or conceptual bandwagon? Media, Culture and Society 36(7): 1032-1044.

Deacon, D and Stanyer, J (2015) 'Mediatization and' or 'mediatization of? A response to Hepp et al. Media, Culture and Society 37(4): 655-657.

Deuze, M (2011) Media life. Media, Culture \& Society 33(1): 137-148.

Giddens, A (1991) Modernity and Self-Identity: Self and Society in the Late Modern Age. Cambridge: Polity Press.

Gregg, M (2011) Work's Intimacy. Cambridge: Polity Press.

Habermas, J (1981/1987) The Theory of Communicative Action. Vol. 2: Lifeworld and System: A Critique of Functionalist Reason. Cambridge: Polity Press.

Hartmann, M (2009) Everyday: Domestication of mediatization or mediatized domestication? In: Lundby, K (ed.) Mediatization: Concept, Changes, Consequences. New York: Peter Lang.

Hepp, A (2009) Differentiation: Mediatization and cultural change. In: Lundby, K (ed.) Mediatization: Concept, Changes, Consequences. New York: Peter Lang, 139-159.

Hepp, A (2011/2013) Cultures of Mediatization. Cambridge: Polity.

Hepp, A (2013) The communicative figurations of mediatized worlds: Mediatization research in times of the 'mediation of everything'. European Journal of Communication 28(6): 615-629. 
Hepp, A, Hjarvard, S and Lundby, K (2015) Mediatization: Theorizing the interplay between media, culture and society. Media, Culture and Society 37(2): 314-324.

Hepp, A and Krotz, F (eds) (2014) Mediatized Worlds: Culture and Society in a Media Age. Basingstoke: Palgrave Macmillan.

Hjarvard, S (2008) The mediatization of society: A theory of the media as agents of social and cultural change. Nordicom Review 29(1): 105-134.

Hjarvard, S (2013) The Mediatization of Culture and Society. London/New York: Routledge.

Hjarvard, S (2014) Mediatization and cultural and social change: An institutional perspective. In: Lundby (2014), 199-226.

Jensen, KB (2013) Definitive and sensitizing conceptualizations of mediatization. Communication Theory 23(3): 203-222.

Kaun, A (2011) Research overview for Riksbankens Jubileumsfond - Mediatisation versus mediation: Contemporary concepts under scrutiny. In: Fornäs, J and Kaun, A (eds) Medialisering av kultur, politik, vardag och forskning (Mediestudier vid Södertörns högskola 2011:2). Huddinge: Södertörns högskola, 16-38 (urn.kb.se/resolve?urn=urn:nbn:se:sh:diva-12829).

Kaun, A and Fast, K (2014) Mediatization of Culture and Everyday Life. Huddinge: Södertörns högskola (www.divaportal.org/smash/record.jsf?searchId=1\&pid=diva2:698718).

Krotz, F (2014) Mediatization as a mover in modernity: Social and cultural change in the context of media change. In: Lundby (2014), 131-161.

Lindell J (2014) Cosmopolitanism in a Mediatized World: The Social Stratification of Global Orientations. Karlstad: Karlstad University Press (dissertation).

Livingstone, S (2009) On the mediation of everything: ICA Presidential Address 2008. Journal of Communication 59(1): 1-18. 
Livingstone, S and Lunt, P (2014) Mediatization: An emerging paradigm for media and communication research? In: Lundby, K (ed.) Mediatization of Communication (Handbooks of Communication Science 21). Berlin/Boston: De Gruyter Mounton, 703723.

Löfgren, $O$ (2009) Domesticated media: Hiding, dying or haunting. In: Jansson, A and Lagerkvist, A (eds) Strange Spaces: Explorations in Mediated Obscurity. London: Ashgate, 57-72.

Lundby, K (2009) Media logic: Looking for social interaction. In: Lundby, K (ed.) Mediatization: Concept, Changes, Consequences. New York: Peter Lang, 101-123.

Lundby, K (ed.) (2014) Mediatization of Communication (Handbooks of Communication Science vol. 21). Berlin/Boston: De Gruyter Mounton.

Lunt, $\mathrm{P}$ and Livingstone, S (in press) Is 'mediatization' the new paradigm for our field? A commentary on Deacon and Stanyer $(2014,2015)$ and Hepp, Hjarvard and Lundby (2015). Media, Culture and Society.

Manheim, E (1933/1979) Aufklärung und öffentliche Meinung. Studien zur Soziologie der Öffentlichkeit im 18. Jahrhundert. Stuttgart/Bad Cannstatt: frommann/holzboog.

Martín-Barbero, J (1993) Communication, Culture and Hegemony: From Media to Mediation. London: Sage.

Mazzoleni, G and Schulz, W (1999) Mediatization of politics: A challenge for politics? Political Communication 16: 247-261.

Meyrowitz, J (1985) No Sense of Place: The Impact of Electronic Media on Social Behavior, Oxford/New York: Oxford University Press.

Morris, JW (2015) Curation by code: Infomediaries and the data mining of taste. European Journal of Cultural Studies 18(4-5): 446-463.

Morrow, R and Brown, D (1994) Critical Theory and Methodology. London: Sage. 
Paasonen, S (2015) As networks fail: Affect, technology and the notion of the user. Television and New Media 6(8): 701-716.

Rakow, L (2013) Worldviews and mediatization: In search of a metatheory. Journal of Multicultural Discourses 8: 190-194.

Ritzer, G (1991) Metatheorizing in Sociology. Lexington, Mass: Lexington Books.

Schulz, W (2004) Reconstructing mediatization as an analytical concept. European Journal of Communication 19(1): 87-101.

Shehata, A and Strömbäck, J (2014) Mediation of political realities: Media as crucial sources of information. In: Esser, F and Strömbäck, J (eds) Mediatization of Politics: Understanding the Transformation of Western Democracies. Basingstoke: Palgrave Macmillan.

Silverstone, R (1999) Why Study the Media? London: Sage.

Strömbäck, J (2011) Mediatization and perceptions of the media's political influence. Journalism Studies 12(4): 423-439.

Strömbäck, J and Dimitrova, Dv (2011) Mediatization and media interventionism: A comparative analysis of Sweden and the United States. The International Journal of Press/Politics 16(1): 30-49.

Thompson, JB (1995) The Media and Modernity: A Social Theory of the Media. Cambridge: Polity Press.

Turow, J , McGuigan, L and Maris, ER (2015) Making data mining a natural part of life: Physical retailing, customer surveillance and the $21^{\text {st }}$ century social imagery. European Journal of Cultural Studies 18(4-5): 464-78.

Virilio, P (1995) The Art of the Motor. Minneapolis: University of Minnesota Press. Williams, R (1977) Marxism and Literature. Oxford: Oxford University Press. 